\title{
Diagnostic dimensionality and transdiagnostic clinical manifestations
}

\author{
Francisco R. de la Peña, ${ }^{1}$ Miriam Feria ${ }^{2}$
}

Unidad de Fomento a la Investigación, Dirección de Servicios Clínicos, Instituto Nacional de Psiquiatría Ramón de la Fuente Muñiz, Ciudad de México, México.

2 Clínica de Adolescentes, Dirección de Servicios Clínicos, Instituto $\mathrm{Na}^{-}$ cional de Psiquiatría Ramón de la Fuente Muñiz, Ciudad de México, México.

Correspondence:

Francisco R. de la Peña

Unidad de Fomento a la Investigación,

Dirección de Servicios Clínicos,

Instituto Nacional de Pisquiatría

Ramón de la Fuente Muñiz.

Calz. México-Xochimilco 101

Col. San Lorenzo Huipulco,

Alcaldía Tlalpan, C.P. 14370

Ciudad de México, México.

Phone: (55) 4160 - 5305

Email: adolesclinic@gmail.com

\section{Citation:}

de la Peña, F. R., \& Feria, M. (2021).

Diagnostic dimensionality and trans-

diagnostic clinical manifestations.

Salud Mental, 44(3), 103-105

DOI: $10.17711 /$ SM.0185-3325.2021.014
For 50 years, a way has been sought to establish the parameters to have valid diagnoses in psychiatry using a scientific approach. Probably the first proposal was the one made for the description of schizophrenia (Robins \& Guze, 1970). This diagnostic approach was based on five parameters: The clinical description not only of the symptoms but also of psychosocial characteristics; laboratory studies; the delimitation of the disorders among themselves; follow-up to determine evolution and family and genetic studies. Shortly thereafter the treatment response parameter was added (Feighner et al., 1972). These six criteria were a fundamental part of the classifying principles of the Diagnostic and Statistical Manual of Mental Disorders in its third edition (DSM-III) published by the American Psychiatric Association (APA) (APA, 1980), and have persisted up to the present in the DSM-5 (APA, 2013); however, today this model has several limitations. The clinical descriptions of the current diagnoses are complex and involve symptoms in cognition, affects, behaviors and social relationships; same that are present among the different categories, which generates shared clinical manifestations. This situation impedes an adequate categorical delimitation. Current detailed brain function and imaging approaches, laboratory or genetic studies are still not of complete diagnostic utility in day-to-day clinical work in psychiatry. Follow-up studies and long-term treatments have only partially helped to understand some aspects of the pathophysiology of disorders and their evolution over time.

These classification problems in psychiatry have been common in both the DSM and the International Classification of Diseases (ICD) of the World Health Organization (WHO). The lack of agreement between the diagnostic criteria of both classification systems has also been very great. It is worth mentioning that the harmonization between the DSM-IV (APA, 1994) and the ICD-10 (WHO, 1992) was only complete for the diagnosis of tics disorders (Andrews, Slade, \& Peters, 1999). This situation has changed at least partially because the classification of mental disorders that is proposed in the ICD-11 (WHO, 2020 ) is currently much more similar to DSM-5 compared to previous editions. There are 31 disorders with the same diagnostic criteria and 10 additional disorders that differ only in the greater degree of operative specificity that DSM-5 has compared to ICD-11. Nineteen categories of ICD-11 disorders that do not appear in DSM-5 and seven categories of DSM5 disorders that do not appear in ICD-11 are described. When comparing 103 diagnoses that appear in both systems, 20 disorders have important differences and 42 have minor definitional differences. Ten disorders have minor differences due to a higher degree of specification in DSM-5, and 31 disorders are practically identical (First et al., 2021). Minor differences are present in just over $40 \%$ of diagnoses; these differences are not random or arbitrary but rather correspond to different priorities of the APA and WHO, in addition to different interpretations of the evidence in both classification systems. (Rutter, 2011). Probably one of the new interests for diagnoses in ICD-11 is the clinical utility (Reed et al., 2018). In contrast to validity, a diagnostic category may be said to possess utility if it provides non-trivial information around prognosis and treatment outcomes, and may be tested for biological and social correlates (Kendell \& Jablensky, 2003). Even more, utility means that clinicians perceived that classifications may improve communication with patients, diagnoses could be more accurate, and constitute a useful tool for clinical management de- 
cisions (Reed, 2018), suggesting that they might be helpful for reducing the global burden of such diseases though their early identification and treatment.

In addition to the differences between the classifications and the particular interests that the APA and the WHO may have, the clinician faces new challenges for the diagnostic establishment, where probably one of the most important is when the symptoms are shared among several diagnoses. This familiarity or symptomatological commonality seems to be the substrate in the construction of the diagnostic dimensions.

We can currently identify several dimensions. For children and adolescent population three dimensions have been described: Neurodevelopmental disorders including diagnoses such as intellectual disability, autism spectrum disorders, and attention deficit hyperactivity disorder. Internalized disorders are integrated with depressive, anxious, obsessive compulsive, and stress-related disorders. Externalized disorders include oppositional and defiant disorder, conduct disorder, and other impulse control disorders, such as intermittent explosive disorder, and even alcohol and drug use disorders (Blanco et al., 2015). For the adult population three dimensions are described: The disturbances in thinking or domain of psychotic experiences, and the internalized and the externalized dimensions (Caspi \& Moffitt, 2018).

The set of all the clinical manifestations of the different disorders constitute what is now known as the "P Factor." This factor is a global representation of psychopathology and is associated with greater deterioration in life, greater family burden of the disease, worse developmental trayectories, and greater compromise of brain function at an early age. This "P Factor" explains why it is difficult to find specific causes, consequences, biomarkers, and treatments for individual mental disorders (Caspi et al., 2014).

The high rates of comorbidity among psychiatric disorders suggest that there is the possibility of a more parsimonious structure that explains psychopathology than that currently described by the DSM-5 and ICD-11 classifications with discrete categories, that is, with the use of dimensions and transdiagnostic constructs.

There are today two important transdiagnostic constructs that have generated much debate between DSM-5 and ICD-11; chronic irritability (Lochman et al., 2015) and limited prosocial emotions (Frick et al., 2003).

Chronic irritability was long a condition considered "diagnostic orphan" as it could be used to identify children and adolescents with unspecified bipolar disorder, depression, anxiety, and oppositional and defiant behaviors. The APA decided to study a category that was called "Severe mood dysregulation" which eventually transformed into "Disruptive mood disregulation disorder" and was included as a mood disorder. Despite this situation, the WHO took a more parsimonious and rational position by including a subtype of oppositional and defiant disorder with the specifier of chronic irritability (Evans et al., 2017). Recently a global field study in which 196 clinicians from 48 countries participated found that by comparing the ICD-10 with the DSM-5, the former led to a more precise identification of severe irritability and better differentiation from boundary presentations. Clinicians using DSM-5 largely did not apply the disruptive mood disregulation disorder when it was appropriate, and they more ferecuently applied psychopathological diagnoses to developmentally normative irritability (Evans et al., 2021). The possibility that chronic irritability may be a transdiagnosis specifier and be included in other disruptive behavior, affective, or neurodevelopmental disorders remains to be studied.

Limited prosocial emotions is a construct that originates from the well-known "emotional callousness" which has worked to identify children and adolescents who present high and persistent antisocial behavior and greater police contacts (Frick et al., 2003; Frick, Stickle, Dandreaux, Farrell, \& Kimonis, 2005). Apparently, the emotional callousness could be a precursor, in children and adolescents with conduct disorder, for the development of psychopathy in adult life (Salekin, Rosenbaum, \& Lee, 2008). It has been shown that subjects with emotional callousness present alterations in the recognition of faces with fear and a reduction in the activity of the brain amygdala (Marsh et al., 2008). Furthermore, emotional callousness traits can be considered a construct not only applicable to disruptive behavior disorders, but also to affective and neurodevelopmental disorders (Herpers, Rommelse, Bons, Buitelaar, \& Scheepers, 2012). Based on this evidence, both the DSM-5 and the ICD-11 decided to include the characteristics of emotional callousness with the name of limited prosocial emotions, in order to reduce the stigma associated with emotional callous, as a specifier of conduct disorder. The ICD-11 expanded the inclusion of the limited prosocial emotions specifier to also apply it to oppositional and defiant disorder. To meet the specifier of limited prosocial emotions, two of the following four characteristics need to be met in the last 12 months: lack of empathy, lack of guilt or remorse, lack of interest in performance, and shallow or deficient affect. Probably the most significant clinical correlate is the outcome of up to $80 \%$ of those children and adolescents with conduct disorder and limited prosocial emotions to an antisocial personality disorder (de la Peña, Villavicencio, \& Palacios, 2017). It is very likely that limited prosocial emotions may be a transdiagnostic specifier and be included in other disruptive behavior, affective or neurodevelopmental disorders.

In conclusion, a gradual diagnostic transformation can be seen from the categorical to the dimensional. The dimensions allow a better understanding of the daily clinical reality and help the doctor, the patient and their family members to understand psychopathology and the many and varied treatment options often required. Transdiagnostic manifestations will be a reality in the way of understanding particular characteristics for each patient. 


\section{REFERENCES}

American Psychiatric Association [APA]. (1980). Diagnostic and statistical manual of mental disorders (DSM-III), 3rd Ed. Washington, D.C.: American Psychiatric Association.

American Psychiatric Association [APA]. (1994). Diagnostic and statistical manual of mental disorders (DSM-IV), 3rd. Ed. Washington, D.C.: American Psychiatric Association.

American Psychiatric Association [APA]. (2013). Diagnostic and statistical manual of mental disorders (DSM-5), 5th Ed. Arlington, VA: American Psychiatric Publishing.

Andrews, G., Slade, T., \& Peters, L. (1999). Classification in psychiatry: ICD-10 versus DSM-IV. The British Journal of Psychiatry, 174(1), 3-5. doi: 10.1192/ bjp. 174.1 .3

Blanco, C., Wall, M. M., He, J. P., Krueger, R. F., Olfson, M., Jin, C. J., ... Merikangas, K. R. (2015). The space of common psychiatric disorders in adolescents: comorbidity structure and individual latent liabilities. Journal of the American Academy of Child \& Adolescent Psychiatry, 54(1), 45-52. doi: 10.1016/j. jaac.2014.10.007

Caspi, A., \& Moffitt, T. E. (2018). All for one and one for all: Mental disorders in one dimension. American Journal of Psychiatry, 175(9), 831-844. doi: 10.1176/ appi.ajp.2018.17121383

Caspi, A., Houts, R. M., Belsky, D. W., Goldman-Mellor, S. J., Harrington, H., Israel, S., ... Moffitt, T. E. (2014). The p factor: one general psychopathology factor in the structure of psychiatric disorders? Clinical Psychological Science, 2(2), 119-137. doi: 10.1177/2167702613497473

de la Peña, F. R., Villavicencio, L. R., \& Palacios, L. (2017). Trastornos de la conducta disruptiva en la infancia y la adolescencia. In J. R. de la Fuente \& G. Heinze (Eds.). Salud Mental y Medicina Psicológica (pp. 133-140). Ciudad de México, México: Mc Graw Hill.

Evans, S. C., Burke, J. D., Roberts, M. C., Fite, P. J., Lochman, J. E., de la Peña, F. R., \& Reed, G. M. (2017). Irritability in child and adolescent psychopathology: An integrative review for ICD-11. Clinical Psychology Review, 53, 29-45. doi: 10.1016/j.cpr.2017.01.004

Evans, S. C., Roberts, M. C., Keeley, J. W., Rebello, T. J., de la Peña, F., Lochman, J. E., ... Reed, G. M. (2021). Diagnostic classification of irritability and oppositionality in youth: a global field study comparing ICD-11 with ICD-10 and DSM-5. Journal of Child Psychology and Psychiatry, 62(3), 303-312. doi: 10.1111/jcpp. 13244

Feighner, J. P., Robins, E., Guze, S. B., Woodruff, R. A., Winokur, G., \& Munoz, R. (1972). Diagnostic criteria for use in psychiatric research. Archives of General Psychiatry, 26(1), 57-63. doi: 10.1001/archpsyc.1972.01750190059011

First, M. B., Gaebel, W., Maj, M., Stein, D. J., Kogan, C. S., Saunders, J. B., ... Reed, G. M. (2021). An organization-and category-level comparison of diagnostic requirements for mental disorders in ICD-11 and DSM-5. World Psychiatry, 20(1), 34-51. doi: 10.1002/wps.20825
Frick, P. J., Cornell, A. H., Bodin, S. D., Dane, H. E., Barry, C. T., \& Loney, B. R. (2003). Callous-unemotional traits and developmental pathways to severe conduct problems. Developmental Psychology, 39(2), 246-260. doi: 10.1037/0012-1649.39.2.246

Frick, P. J., Stickle, T. R., Dandreaux, D. M., Farrell, J. M., \& Kimonis, E. R. (2005). Callous-unemotional traits in predicting the severity and stability of conduct problems and delinquency. Journal of Abnormal Child Psychology, 33(4), 471487. doi: 10.1007/s10648-005-5728-9

Herpers, P. C., Rommelse, N. N., Bons, D. M., Buitelaar, J. K., \& Scheepers, F. E. (2012). Callous-unemotional traits as a cross-disorders construct. Social Psychiatry and Psychiatric Epidemiology, 47(12), 2045-2064. doi: 10.1007/ s00127-012-0513-x

Kendell, R., \& Jablensky, A. (2003). Distinguishing between the validity and utility of psychiatric diagnoses. American Journal of Psychiatry, 160(1), 4-12. doi: 10.1176/appi.ajp.160.1.4

Lochman, J. E., Evans, S. C., Burke, J. D., Roberts, M. C., Fite, P. J., Reed, G. M., ... Garralda, M. E. (2015). An empirically based alternative to DSM-5's disruptive mood dysregulation disorder for ICD-11. World Psychiatry, 14(1), 30-33. doi: 10.1002/wps. 20176

Marsh, A. A., Finger, E. C., Mitchell, D. G., Reid, M. E., Sims, C., Kosson, D. S., ... Blair, R. J. R. (2008). Reduced amygdala response to fearful expressions in children and adolescents with callous-unemotional traits and disruptive behavior disorders. American Journal of Psychiatry, 165(6), 712-720. doi: 10.1176/appi.ajp.2007.07071145

Reed, G. M., Keeley, J. W., Rebello, T. J., First, M. B., Gureje, O., Ayuso-Mateos, J. L., ... Medina-Mora, M. E. (2018). Clinical utility of ICD-11 diagnostic guidelines for high-burden mental disorders: results from mental health settings in 13 countries. World Psychiatry, 17(3), 306-315. doi: 10.1002/wps.20581

Robins, E., \& Guze, S. B. (1970). Establishment of diagnostic validity in psychiatric illness: its application to schizophrenia. American Journal of Psychiatry, 126(7), 983-987. doi: 10.1176/ajp.126.7.983

Rutter, M. (2011). Research review: Child psychiatric diagnosis and classification: concepts, findings, challenges and potential. Journal of Child Psychology and Psychiatry, 52(6), 647-660. doi: 10.1111/j.1469-7610.2011.02367.x

Salekin, R. T., Rosenbaum, J., \& Lee, Z. (2008). Child and adolescent psychopathy: Stability and change. Psychiatry Psychology and Law, 15(2), 224-236. doi: 10.1080/13218710802014519

World Health Organization [WHO]. (1992). The ICD-10 classification of mental and behavioural disorders: Clinical descriptions and diagnostic guidelines. Retrieved from https://www.who.int/classifications/icd/en/bluebook.pdf

World Health Organization [WHO]. (2020). International Statistical Classification of Diseases and Related Health Problems (ICD), (10th and 11th revisions). Retrieved from: https://www.who.int/classifications/icd/en/ 